\title{
RAÇA E COMPORTAMENTO POLÍTICO: PARTICIPAÇÃO, ATIVISMO E RECURSOS EM BELO HORIZONTE*
}

Natália S. Bueno

A discussão sobre raça na política brasileira é mote entre cientistas sociais de diversas perspectivas: pelo seu papel na formação do Estado nacional, nos movimentos sociais ou ainda nas políticas públicas voltadas a grupos raciais. Mas, pela maior parte da ciência política brasileira, é rapidamente descartada como irrelevante ou residual. Este texto, no entanto, toma o lugar da raça na política como uma questão central e propõe as seguintes questões: Qual é o papel da raça no comportamento político dos indivíduos? De que maneira o pertencimento a um grupo racial se expressa na atuação política? Qual é a interação entre raça e recursos como determinantes da participação?

Para pensar as relações entre raça e comportamento político, uma das tradições de pesquisa mais estabelecidas em ciência política, por seus achados empíricos consistentes, argumenta que indivíduos com maior posse de recursos socioeconômicos, assim como orientações psicológicas

* Este texto é parte da pesquisa apresentada em Bueno (2010). Agradeço a Adrian Gurza Lavalle, pela orientação minuciosa e rigorosa, e a Bruno Reis, George Avelino e Antonio Sérgio Alfredo Guimarães, pelos comentários e sugestões. 
mais cívicas em relação à política, tendem a ser mais ativos politicamente (Leighley, 1995, 2008; Schlozman, 2002). Em outras palavras, a abordagem traz, para a análise do comportamento político, variáveis demográficas que denotam a posição social do indivíduo e, assim, a dotação de recursos que lhe permite superar os custos inerentes à participação política (Timpone, 1998). Tal tradição atende por vários nomes: modelo do status socioeconômico (SES), teoria da mobilização de recursos (resource mobilization theory) ${ }^{1}$, modelo da centralidade, ou, simplesmente, abordagem dos recursos. Sua proposição central é amplamente reconhecida e implicitamente incorporada nas análises sobre comportamento político - como, aliás, Norris e Inglehart levam a cabo na sua análise de World Value Survey (Bowers, 2008; Achen, 1992; Schlozman, 2002; Norris, 2002; Inglehart e Norris, 2003).

As hipóteses dessa abordagem, em especial as que 188 associam maior dotação de recursos socioeconômicos e maior probabilidade de participação política, foram testadas nos mais diversos contextos. Tal abordagem se tornou lugar comum em estudos sobre comportamento político, como atestam os manuais de ciência política (Dalton e Klingemann, 2007; Goodin e Klingemann, 1996). Na ciência política nacional, em especial nos estudos eleitorais até meados dos anos 1990, a abordagem dos recursos, nas suas diversas variações, foi utilizada e discutida por vários autores (Reis, 2000, 2001; Castro, 1993; Fuks e Perissinotto, 2006; Ribeiro e Borba, 2011).

No entanto, o encontro entre essa literatura e o debate racial pouco ocorreu na ciência política nacional, sendo que, no caso da literatura estadunidense, a raça teve papel

\footnotetext{
1 Vale notar que não se trata da abordagem de recursos utilizada para estudos de movimentos sociais e ação coletiva usualmente associada a, dentre outros, McAdam (1982).
} 
proeminente $^{2}$ nos estudos sobre comportamento político orientados por essa vertente. Na literatura brasileira, a principal questão se voltou para a existência ou não de um "efeito da raça" e se o comportamento de brancos e negros (pretos e pardos) apresentaria padrões distintos - para além da classe, que, de saída, está fortemente associada à raça. Em resposta a essa pergunta, analisada através do enquadramento da abordagem centrada em recursos, argumenta-se neste artigo que, no Brasil, o pertencimento a um grupo racial não afeta de forma substantiva a propensão a atuar politicamente, ao passo que fatores socioeconômicos, como renda e escolaridade, são nitidamente mais relevantes. Esses resultados empíricos, por sua vez, não eliminam o fato de que a abordagem dos recursos apresenta limitações para testar os fatores que levariam à mobilização racialmente orientada no Brasil.

Este texto é composto de quatro seções. Na primeira e na segunda partes, discutem-se as literaturas sobre a abordagem dos recursos e raça e comportamento político no Brasil. A terceira seção apresenta a metodologia, a base de dados e as análises realizadas. E, por fim, a quarta seção traz considerações finais sobre o papel da raça no comportamento político a partir dos dados analisados.

\section{Raça na abordagem baseada em recursos}

No Modelo do Voluntarismo Cívico (CVM) apresentado em Voice and equality (Verba, Schlozman e Brady, 1995), indivíduos participam porque: a) têm os recursos socioeconômi-

\footnotetext{
2 Logo após as mobilizações do movimento pelos direitos civis, o principal problema sobre o qual os cientistas políticos interessados no tema se debruçavam era o seguinte: as minorias raciais nos Estados Unidos tinham sido incluídas na poliarquia, mas restava avaliar se a igualdade política havia sido atingida. Desde então, a questão racial foi incorporada nas análises de Verba e seus colaboradores, mas também por parte significativa dos autores preocupados com os determinantes do comportamento político.
} 
cos necessários e competências (civic skills) ${ }^{3}$ adquiridas; b) querem, movidos pela orientação cívica, por uma percepção de competência subjetiva ou por interesse em política, por exemplo; e c) foram incitados, convidados por alguém (recruitment). Apesar de essas três dimensões comporem o CVM, é importante ressaltar - como os próprios autores o fazem (Verba, Schlozman e Brady, 1995, pp. 269-287) que os recursos são os elementos principais desse modelo. O pressuposto geral subjacente à abordagem baseada em recursos se funda na ideia de que participar é custoso, de modo que é necessária a posse de recursos que permita que o indivíduo seja capaz de superar os impedimentos de custos à participação. Em outras palavras, segundo os autores, os recursos são essenciais porque tornam possível a participação; permitem que indivíduos possam dedicar parte de seu tempo à política. Assim, são anteriores e condicionantes dos outros fatores.

190 Ainda que o CVM especifique dinheiro, tempo e habilidades cívicas como os principais recursos (Verba, Schlozman e Brady, 1995, pp. 270-271), esses últimos são definidos por um conjunto heterogêneo de fatores: desde nível educacional e renda a predisposições psicológicas à participação política. Apesar de a definição de recursos não se referir à noção de raça diretamente, a questão racial não está em segundo plano nos textos de Verba e seus coautores. Em seus estudos empíricos, Verba, Schlozman e Brady (1995) afirmam que negros são um pouco menos ativos do

\footnotetext{
3 Habilidade cívicas são definidas como "as habilidades comunicativas e organizacionais que permitem que os cidadãos usem seu tempo e dinheiro efetivamente na atuação política" (Verba, Schlozman e Brady, 1995, p. 320). Os principais argumentos que motivam e sustentam a inclusão dessas variáveis se referem ao potencial de aprendizado e socialização em organizações não políticas, como igrejas, clubes recreativos, associações de caridade e assistência. As habilidades cívicas são vistas como um "recurso cognitivo" que impulsiona o indivíduo à participação. Dessa maneira, grupos com poucos recursos, como dinheiro, tempo e, inclusive, educação, podem ser mais politicamente ativos do que o esperado se eles tiverem acesso a espaços para o desenvolvimento dessas habilidades.
} 
que brancos e latinos são significativamente menos ativos (Verba, Schlozman e Brady, 1995, p. 263). Os autores sugerem que, se as diferenças em termos de posse de recursos entre os grupos raciais são controladas, a disparidade em atividades políticas não se sustenta (Verba, Schlozman e Brady, 1995, p. 523).

De qualquer maneira, destacam os autores, é importante reconhecer que diferenças associadas com raça, principalmente a religião, afetam diretamente as chances de participar. Latinos são, em sua maioria, católicos, e negros são, na maior parte, protestantes. Isso significa que, para os primeiros, a experiência religiosa não traz a aquisição de habilidades que podem ser utilizadas como recurso à participação política, ao passo que, para os segundos, a experiência em organizações religiosas traz benefícios significativos às suas habilidades cívicas.

Em artigo dedicado somente a raça e participação política nos Estados Unidos, os autores sustentam o mesmo argumento (Verba, Schlozman, Brady e Nie, 1993, pp. 457-458): "diferenças na participação política entre grupos raciais e étnicos devem ser entendidas no contexto das suas posições socioeconômicas distintas: grupos com menos renda e escolaridade são menos ativos politicamente”. Dessa maneira, raça é uma dimensão relevante desde que associada com a posição socioeconômica; e, ainda outros fatores, como religião e língua, são mobilizados por grupos raciais como recursos (habilidades) (Verba, Schlozman, Brady e Nie, 1993, p. 458). Em síntese, a raça só é relevante se lida como um fator associado ao desenvolvimento de uma habilidade - e, portanto, um recurso.

Uma literatura mais recente vem mostrando que a relação entre raça, etnicidade e recursos não pode ser facilmente reduzida aos recursos, mesmo recursos como língua e religião (Leighley e Vedlitz, 1999; Leighley e Matsubayashi, 2009; Cho, Gimpel e Wu, 2006; Segura e Rodrigues, 2006; 
Chandra, 2006). Esses textos, assim como um conjunto de outros artigos e livros, apresentam críticas pontuais à abordagem de recursos tal como formulada no modelo do voluntarismo cívico e propõem, menos do que um deslocamento analítico na relação entre raça e recursos, refinamentos e maior precisão na maneira com que raça é incorporada no modelo.

Cho, Gimpel e Wu (2006), por exemplo, analisam a mobilização de árabes-americanos e testam tanto o modelo SES quanto a perspectiva da mobilização. Segundo esses autores, recursos socioeconômicos têm seus efeitos mediados em minorias étnicas, uma vez que o pertencimento a esses grupos configura o que indivíduos aprendem e sabem sobre política, ou seja, como eles apreendem o mundo da política. Já Wrinkle, Stewart Jr., Polinard, Meier e Arvizu (1996), ao tratarem da participação política não eleitoral entre hispânicos, afirmam que, como esperado pela litera192 tura, quanto maior a posse de recursos, maior a probabilidade de participar. Entretanto, eles encontram diferenças interessantes entre os grupos hispânicos, tendo os indivíduos de ascendência cubana um comportamento distinto de indivíduos com ascendência mexicana e porto-riquenha. A situação política excepcional dos cubanos nos Estados Unidos, as relações entre Castro e o governo norte-americano e o perfil etário da comunidade cubana nos EUA também são levados em consideração para explicar as diferenças entre os grupos.

Por sua vez, Leighley e seus colaboradores (Leighley e Vedliz, 1999; Leighly e Matsubayashi, 2009) chamam a atenção para a necessidade analítica de dissociar raça e recursos socioeconômicos. Para esses autores, fatores não associados a recursos, como conflitos intra e entregrupos e redes sociais, são cruciais na explicação generalizável, válida para distintos grupos e não só referentes às diferenças entre brancos e negros ou de raça e participação. Mais especifi- 
camente, Leighley e Matsubayashi (2009) destacam que a maior parte dos estudos acerca dos efeitos de redes sociais na atuação política de indivíduos não inclui o debate sistemático ou mesmo analisa a dimensão racial e étnica. A omissão da dimensão racial é grave porque a composição racial das redes políticas dos indivíduos pode ter efeitos significativos no comportamento político e nas atitudes, uma vez que "minorias raciais e étnicas tendem a ter redes sociais menores e menos especializadas em conhecimento político, de modo que não se beneficiam dos atalhos informacionais que as redes tendem a proporcionar para brancos” (Leighley e Matsubayashi, 2009, p. 848).

Segura e Rodrigues (2006) se somam ao grupo mais crítico do modelo proposto por Verba e seus colaboradores. As autoras acusam contundentemente a ausência de textos sobre "outras minorias raciais" - além da relação entre brancos e afro-americanos - nos Estados Unidos. Para elas, fatores tipicamente associados a novas minorias raciais, como os padrões de imigração, não são sistematicamente incluídos nos debate sobre comportamento e atitudes políticas (Segura e Rodrigues, 2006, pp. 378-380). Além do mais, questões de identidade e consciência grupal são drasticamente distintas não só entre latinos, asiáticos e negros, mas também entre os próprios latinos e asiáticos. Nesse sentido, a experiência racial está muito além da posse de recursos, pois é contingente a padrões de incorporação de indivíduos, que são, de certo modo, composições demográficas mais amplas da polity.

Uma vertente de críticas reaviva o debate sobre consciência e solidariedade racial, especialmente intenso nos anos 1980 (Shingles, 1981; Miller, Gurin, Gurin e Malanchuk, 1981; Bobo e Gilliam, 1990; mais atualmente Hutchings e Valentino, 2004; Chong e Rogers, 2005). McClain, Carew, Walton e Watts (2009) não só retomam o debate sobre noções como consciência de grupo, pertencimento e iden- 
tidade, mas também discutem os diversos modos com que essas noções são utilizadas e seus efeitos distintos. Chamam a atenção, dessa forma, para os problemas em usá-las alternadamente, assim como em transferir as premissas e hipóteses das análises sobre negros (blacks) para outras minorias raciais - no caso estadunidense.

Chong e Rogers (2003, 2005) e Chong e Kim (2006) assinalam que a maior parte dos estudos após os anos 1980 subestimaram os efeitos da consciência e identificação raciais devido a problemas de conceitualização e mensuração desses fatores. Mais: argumentam que medidas apropriadas de consciência e identificação raciais para latinos e asiáticos são contingentes ao conteúdo de group-based ideologies, tanto que as ideologias associadas a negros não só variaram de acordo com perfil intraracial (black nationalists versus civil rights activists), mas também ao longo do tempo. Por fim, ainda propõem uma interação entre status socio194 econômico e raça condicionada pela experiência racial de cada grupo (Chong e Kim, 2006, p. 348) ${ }^{4}$.

Em síntese, as críticas mais incisivas ao CVM sublinham a necessidade de imputar status analítico distinto para raça, ou seja, que sua operação não seja simplesmente através de recursos adquiridos.

De certa forma, essa vertente de debate que chama a atenção para a solidariedade e consciência racial vai ao encontro aos primeiros trabalhos de Verba e seus coautores (em trabalhos anteriores ao CVM). Nesses trabalhos, Verba e Nie (1972) encontram a seguinte configuração da participação política por grupos raciais nos Estados Unidos. Em primeiro lugar, em média, brancos são mais ativos do que negros. Embora, novamente em média, brancos participem

\footnotetext{
4 Os autores explicam essas diferenças residuais pelo evento do movimento pelos direitos civis, que gerou uma espécie de crença no valor instrumental da solidariedade racial como recurso político por parte dos afro-americanos (Chong e Kim, 2006, p. 349).
} 
mais do que negros (o que era esperado de acordo com as posições sociais médias de cada grupo), esse achado não é constante para todas as formas de participação política (Verba e Nie, 1972, pp. 149-173). E ao analisar brancos e negros com os mesmos patamares socioeconômicos, encontra-se que negros são, em realidade, tão ou mais ativos do que brancos (Verba e Nie, 1972, p. 157). A explicação para esse achado passa, no trabalho de Verba e Nie, pela questão da consciência ou solidariedade de grupo com base no atributo racial (group consciousness), ou seja, pela percepção (awareness) de um status socioeconômico compartilhado entre indivíduos do mesmo grupo racial (Verba e Nie, 1972, p. 173).

Verba, Nie e Kim (1978) colocam seu próprio modelo à prova, para além das fronteiras estadunidenses. Os autores encontram que a associação entre recursos socioeconômicos e participação não segue, à primeira vista, padrão tão positivo e forte nos diversos países como no caso estadunidense. Dessa maneira, os autores propõem um modelo no qual, além dos fatores individuais (recursos), fatores coletivos ou institucionais teriam um papel relevante. Sem a "interferência" dos fatores institucionais (entendidos pelos autores como partidos políticos e associações voluntárias $)^{5}$, os recursos socioeconômicos seriam convertidos em participação política (Verba, Nie e Kim, 1978, pp. 80-81, 92-93).

As clivagens sociais seriam relevantes para mobilização política na medida em que elas se refletem no sistema institucional dos países, principalmente pela base populacional mobilizada por partidos e associações voluntárias (Verba, Nie e Kim, 1978, pp. 157-158). Desse modo, se as instituições políticas não espelham nas suas bases a raça como clivagem social politicamente saliente, ela não é relevante para

5 Devido a suas diversas funções como canais de comunicação entre cidadãos e governo (via mobilização, abertura de oportunidades de participação, atuação no debate público). 
a atuação política ${ }^{6}$. E, ainda, no trabalho sobre os Estados Unidos, raça é contingente a uma percepção compartilhada e consciência de grupo. Se raça fosse puramente associada a desigualdades socioeconômicas ou a experiências de socialização (língua, experiências de discriminação) distintas entre grupos raciais, mas ainda não coesas ou compartilhadas dentro dos grupos raciais, raça não seria fator relevante. Raça somente opera na medida em que há uma consciência coletiva e percepção de grupo compartilhada.

De modo geral, todos esses autores disputam o significado e os mecanismos relacionados à noção de raça. No CVM, presume-se que raça é politicamente relevante quando existem grupos raciais que compartilhem práticas (língua e religião, por exemplo) e espaços (associações) que levam a habilidades e recursos politicamente relevantes. $\mathrm{Ou}$ seja, raça é relevante quando se desenvolvem habilidades (um tipo de recurso) em ambientes racialmente exclusivos 196 e homogêneos. Essa proposta, apesar de plausível, depende de um tipo específico do desenvolvimento racial cujo caso empírico fartamente documentado é o estadunidense. Paralemente, outros autores chamam a atenção para fatores associados à raça que não estão incluídos no CVM, especialmente via consciência racial. Essas críticas e até trabalhos anteriores de Verba e seus colaboradores oferecem um enquadramento mais amplo de mecanismos e efeitos da raça em outras polities.

\section{Raça e comportamento político no Brasil}

Os estudos sobre raça e política no Brasil se dividem, em termos gerais, entre aqueles que discutem a história e a organização do movimento negro e os que estudam a repre-

\footnotetext{
${ }^{6}$ Caso o Brasil estivesse sob escrutínio, tendo em vista a literatura sob clivagens sociais e mobilização política brasileira, raça não seria uma clivagem refletida nas instituições e, portanto, não seria politicamente relevante para a mobilização política.
} 
sentação política e o comportamento eleitoral de grupos raciais. O ponto de fuga de grande parte dos trabalhos que analisam raça e atuação política no Brasil é a dicotomia e a interação entre o pertencimento a um grupo racial e a inserção em classes sociais. Devido à saliência das desigualdades e os conflitos orientados por critérios socioeconômicos - frouxamente nomeados aqui como classe -, a relação entre essas duas categorias permeou os principais trabalhos nos estudos sobre raça e política. Ainda que exista um consenso de que grupos raciais estão em posições socioeconômicas distintas e que não brancos ${ }^{7}$ estão em piores posições nos indicadores socioeconômicos, há um intenso debate quase beligerante acerca das causas efetivas (preconceito e discriminação versus mecanismos "de classe") que explicariam essas diferenças (Hasenbalg, 2005; Hasenbalg, Valle Silva e Lima, 1999; Santos, 2005; Souza, 2006). Dessa maneira, os trabalhos sobre raça e política no Brasil orientam suas análises para responder três questões: Qual é a saliência da mobilização racial no Brasil? Há efeitos do pertencimento racial na mobilização política no Brasil? Quais fatores geram essa mobilização política racialmente orientada? De qualquer maneira, a principal preocupação da literatura brasileira é identificar o "efeito" da raça na política, e especialmente diferenciá-lo, se possível, do efeito da classe.

Os trabalhos sobre o chamado movimento negro constituem, muito provavelmente, o principal campo de estudos sobre raça e política no Brasil. A maior parte dos trabalhos nesse campo abordam a evolução desse movimento e, em certo sentido, inserem-se na primeira pergunta listada acima.

Movimentos com a bandeira racial não adquiriram uma adesão em larga escala (como ocorreu no Civil Rights Move-

7 É importante destacar que brancos, pardos e pretos não são os únicos grupos raciais no Brasil. Mas, de acordo com o censo de 2000, esses três grupos representam 98\% da população brasileira ver IBGE (s.d.). 
ment, nos EUA, ou no Black Consciousness Movement, entre outros, na África do Sul) e a literatura sobre movimentos sociais e mobilização coletiva no Brasil esteve fortemente associada a movimentos ligados ao trabalhismo (Guimarães, 2008). Talvez devido à baixa politicização da clivagem racial, grande parte do movimento negro se caracterizou pelo "ativismo cultural", com demandas e atividades de cunho mais cultural do que estritamente político. Pode-se afirmar que a principal preocupação da Frente Negra Brasileira (FNB) foi, no início do século XX, com a integração dos negros na sociedade brasileira. O Movimento Negro Unificado (MNU), cujo início se deu nos anos 1970, possivelmente pode ser indicado como o movimento mais bem-sucedido no Brasil desde a Abolição da Escravidão (Andrews, 1991, 1996) - mesmo que sua atuação política tenha registro fortemente cultural, com a defesa de uma cultura e identidades negras particulares, como o Black Soul nos anos 1970 198 (Hanchard, 1993, 2001; Cardoso, 2001).

Porém, desde 1985, podem ser identificadas mudanças substantivas no movimento negro, que passou, simultaneamente, a afirmar uma identidade própria, para além do movimento trabalhista (mas muitas vezes se associando ao feminismo), e a colocar em pauta demandas políticas, como políticas afirmativas para o ensino superior. O MNU, por exemplo, tomou como posição um racialismo radical com o afrocentrismo expresso no quilombismo proposto por Abdias do Nascimento. Nos anos 1980 e 1990, várias organizações surgiram para abordar a agenda racial, que vai desde a implementação de políticas de reconhecimento, a luta contra o racismo e preconceito até a criação de políticas afirmativas e de redistribuição (Htun, 2004) ${ }^{8}$. As reivindicações por políticas e legislação contra a discrimina8 Ver Muniz (2010) para um breve levantamento de políticas de ação afirmativa
desde 1988. 
ção, assim como por redução das desigualdades raciais, são nitidamente diferentes das demandas culturais - tradicionalmente mais palatáveis ao Estado brasileiro como parte do mito fundacional oficial do sincretismo entre indígenas, negros e brancos (Guimarães, 2003). E, adicionalmente, como mostra Rios (2008), há evidências robustas de que as organizações que compõem o chamado movimento negro vivem um processo de institucionalização, em especial na década de 1990, na qual passam a adotar o rótulo de organizações não governamentais (ONGs) e a atuar pelo registro de prestação de serviços e advocacy, distanciando-se das mobilizações e protestos próprios aos anos 1970 e 1980. Mais: conferências internacionais como a Conferência Mundial sobre o Racismo, em 2001, em Durban (África do Sul), foram muito importantes para legitimar o movimento negro e denunciar o racismo (Paschel e Sawyer, 2008; Sawyer, 2005).

Apesar da existência dessa mobilização, existe algum acordo na literatura que sustenta que raça não foi um fator efetivo na formação de uma percepção de identidade de grupo (Sansone, 2003) e que, se há algum fator capaz de articulação política no Brasil, ele está associado a classe e posição socioeconômica (Reis, 2001). Telles (1996, 2003) aponta que fatores usualmente associados à identidade afro-descendente, como religião e até cor de pele, assim como elementos estruturais como segregação residencial, não eram suficientemente exclusivos de afro-descendentes. Dessa maneira, diferentemente do caso estadunidense, esses fatores não produziram uma linha saliente e nítida entre brancos e negros, que poderia levar ao estabelecimento de uma identidade racial amplamente compartilhada. Segundo Hasenbalg (2005), a aquiescência social de negros no Brasil foi causada por três fatores: 1) cooptação social (que converte as aspirações coletivas para busca do bem-estar econômico e social em desejos individuais de mobilidade); 2) 
manipulação ideológica; e 3) o uso da ameaça ou repressão. Esses fatores explicariam porque "a afiliação racial não conseguiu proporcionar o laço coletivo para estimular as demandas dos negros por mobilidade social grupal e pela diminuição das desigualdades raciais" (Hasenbalg, 2005, p. 233).

Apesar de os estudos sobre movimentos sociais indicarem que raça não é a clivagem central da mobilização política, eles mostram a existência de grupos e organizações voltados para a questão racial na política. E essas organizações não estão ausentes de efeitos na arena eleitoral, legislativa ou executiva.

Um conjunto de autores discute o papel da raça em estratégias e campanhas eleitorais, assim como na atuação de parlamentares (Mitchell, 2009; Johnson, 1998, 2006; Santos, 2000; Oliveira, 1997, 2007). Esses autores não encontram, em termos gerais, evidência de um tipo de voto

200 racialmente orientado (de eleitores negros para candidatos negros), apesar de, em alguns casos, existirem estratégias eleitorais bem-sucedidas de candidatos negros com grande ênfase na questão racial. De qualquer modo, esses autores apontam para o papel do movimento negro em apoiar e militar em prol de candidatos negros ou, ainda, de pressionar representantes no executivo e legislativo, com graus diversos de êxito (Johnson, 2006, p. 172).

Nessa literatura, há consenso entre os autores de que negros são drasticamente sub-representados no legislativo, mesmo em cidades com expressiva população negra como Salvador (BA), em especial (Oliveira, 1997). Os autores também mostram que, mesmo entre os representantes negros eleitos não há coesão e consenso sobre o tipo de política racial a ser adotada ou, ainda, se a questão racial é publicamente legítima (Mitchel, 2009, p. 132; Santos, 2000). Por fim, vale notar que a tensão entre raça e classe não está ausente desse debate: muitos representantes e 
candidatos negros têm origem em classes trabalhadoras e sua militância de classe frequentemente se sobrepõe ou supera a militância na questão racial (Mitchel, 2009; Oliveira, 1997).

Os estudos sobre comportamento eleitoral adotaram uma perspectiva distinta e colocaram nitidamente a pergunta sobre os efeitos da raça: Em que medida desigualdades sociais, além de práticas discriminatórias, expressam-se em um comportamento eleitoral diferenciado por grupos raciais (Lamounier, 1968; Souza, 1971; Berquó e Alencastro, 1992; Guimarães, 2002; Soares e Valle Silva, 1987)? Vale destacar que, diferentemente da literatura sobre movimento negro, a unidades de análise aqui não são mais organizações e entidades, mas sim indivíduos (eleitores) cujos determinantes e formas de mobilização são distintos daqueles descritos pela literatura centrada em organizações e movimentos sociais. É importante ter essa distinação analítica em mente, pois frequentemente diagnósticos sobre a mobilização organizacional (por estudos de caso, análise de documentos e mesmo surveys organizacionais) e societal (frequentemente identificada por survey de indivíduos) apresentam descrições que não necessariamente coincidem.

Souza (1971), por exemplo, argumenta que negros expressam mais intensamente a preferência por partidos e candidatos tidos como populistas comparados com eleitores brancos, mesmo quando estão numa posição social superior. Soares e Valle Silva (1985) também encontram uma tendência entre pardos a votar por candidatos populistas, especialmente aqueles considerados "herdeiros" políticos de Vargas. Castro (1993) encontrou uma discrepância do voto negro, variando de um alto grau de apatia a expressões mais intensas de radicalismo, dependendo da posição social ocupada pelo indivíduo. Indivíduos negros de estratos mais baixos tendem a ser mais apáticos (ou alienados, segundo 
a autora), anulando os votos ou votando em branco. Por outro lado, indivíduos negros de estratos mais altos, especialmente aqueles com mais escolaridade, tendem a não só anular menos os votos, mas a escolher candidatos mais frequentemente identificados como radicais de esquerda. Em síntese: "pertencer a um grupo racial pode, por exemplo, intensificar, em alguns casos, ou impedir, em outros, a manifestação de tendências dadas pela posição social" (Castro, 1993, p. 483).

Prandi (1996) aponta que, apesar de a raça afetar a escolha eleitoral, ela não é o principal determinante: idade e escolaridade superaram-na como os principais preditores da votação presidencial eleitoral de 1994. De qualquer maneira, esse autor indica que houve uma tendência clara de negros votarem no candidato Luís Inácio Lula da Silva, enquanto a maior parte dos brancos declarou votar em Fernando Henrique Cardoso. Bailey (2009), ao analisar a 202 eleição de Benedita da Silva no Rio de Janeiro, também encontra evidências de que há vieses raciais no comportamento do eleitor brasileiro. Ele encontra indicações não só de que a cor do candidato teve efeitos no voto, mas também de que eleitores de diferentes grupos raciais se comportaram distintamente, ainda que a clivagem encontrada tenha sido preto e não preto (e não a clivagem usual de branco e não branco). Apesar das evidências encontradas, o autor pede cautela na interpretação dos resultados e propõe uma síntese interpretativa interessante da literatura à luz dos seus dados:

A relação entre raça e política eleitoral no Brasil não deve ser entendida como uma dualidade, mas sim como uma escala com gradações. Por um lado, Sansone acertadamente aponta que há níveis baixos de mobilização racial e étnica na política e que a identidade racial não se manifesta de modo relevante na esfera eleitoral. Por outro lado, Mitchell 
(1977) e Soares e Silva (1985) podem ter exagerado a dimensão da "consciência racial" entre os não brancos nas eleições que eles analisam. Desse modo, a afirmação ponderada de Castro pode ser a melhor descrição do efeito da identificação racial na esfera político-eleitoral [...] O desenvolvimento de um eleitorado negro pode ser condicionado à classe social (medida por educação). A disjunção entre o movimento negro e grande maioria de não brancos é, nesse sentido, uma explicação plausível entre a falta de mobilização em torno de uma "negritude" (Bailey, 2009, pp. 90-91).

Como já anunciado, os debates giram em torno da relação entre raça e posição social - classe ou, como analisado aqui, recursos ${ }^{9}$. E, em vários autores, encontra-se evidência de alguma condicionalidade ou interação entre raça e classe, ainda que essa ideia só se expresse mais explicitamente em Castro e Bailey (Bueno e Fialho, 2009). E, apesar de a maior parte encontrar certo efeito distinguível do pertencimento a algum grupo racial, poucos autores se aventuram numa explicação sobre os fatores que geram esse comportamento diferenciado - a terceira pergunta listada como orientadora do debate brasileiro. A interpretação, ainda que preliminar e cautelosa, da maioria dos analistas brasileiros é que raça tem algum efeito devido a experiências de discriminação e preconceito sofridas pelos grupos raciais marginalizados - mesmo que essas experiências não signifiquem habilidades específicas e tampouco consciência racial politizada. A discriminação é, provavelmente, apontada como o principal fator suspeito de causar o "efeito da raça" porque é um mecanismo que,

\footnotetext{
9 Aliás, a identificação e especificação do efeito da raça e a diferenciação do efeito da classe e da raça é igualmente majoritário nos debates sobre desigualdade socioeconômica, mobilidade social, entre outras (Bailey, 2008; Muniz, 2010; Bailey, Muniz e Loveman, 2009).
} 
simultaneamente, independe da posição de classe do indivíduo e não é contingente a consciência coletiva de raça ou racismo publicamente institucionalizado. Ou seja, se há algum efeito associado à raça, ele passa por percepções e experiências do pertencimento a grupo racial, como a discriminação e o preconceito.

\section{Raça e comportamento político na região metropolitana de Belo Horizonte}

Apesar do pouco diálogo entre a abordagem dos recursos e a literatura sobre comportamento político e raça no Brasil, propõe-se que a tensão entre classe e raça e a busca do "efeito da raça" podem ser analisados por meio dessa abordagem, uma vez que ela (ao menos no CVM) tem premissas e expectativas nítidas de como a raça deve operar na interação com recursos. Assim, tem-se um instrumento que permite responder as questões sobre raça e política que 204 orientam parte relevante da literatura brasileira.

Este artigo lida com duas medidas de comportamento político: participação em organizações políticas e ativismo político. A participação em organizações políticas se refere à existência de vínculo (formal ou informal) do entrevistado com organizações classificadas como políticas. Assim, devido à presença de algum vínculo do indivíduo entrevistado com alguma organização política, presume-se que o indivíduo participa de organizações políticas. $\mathrm{O}$ ativismo político trata da participação em atividades políticas mais eventuais e pontuais, como protestos, boicotes ou abaixo-assinados.

\section{Base de dados e variáveis}

A análise foi baseada nos dados levantados no projeto do Hubble Social. A Pesquisa de Região Metropolitana de Belo Horizonte (PRMBH), realizada em 2005, é uma amostra probabilística e representativa da população da região 
metropolitana de Belo Horizonte. O total de entrevistas realizadas foi de 1.122 pessoas $^{10}$.

Com relação ao banco de dados, qualquer indivíduo que se identificou como "indígena", "amarelo" (de acordo com as categorias do IBGE) ou "outro" foi excluído da análise $^{11}$. Dois motivos levaram a essa escolha. Primeiramente, o número e a proporção total de indivíduos excluídos foram insuficientes para qualquer análise substantiva. Em segundo lugar, o debate acerca de raça e comportamento político no Brasil aqui discutido tem como objeto a relação entre negros e brancos. A amostra belorizontina utilizada para a análise, depois de corrigida com os pesos amostrais, é de 1.010 casos (999 casos sem a correção por peso amostral $)^{12}$.

\section{Variáveis dependentes}

Participação política. Como mencionado anteriormente, são utilizadas duas variáveis de comportamento político. Para participação em organizações políticas, as seguintes organizações foram computadas: partidos políticos, associações de proteção ao consumidor, comunitárias ou de vizinhança ${ }^{13}$, partidos políticos, negócios e comércio, movimentos estudantis, sindicatos, associações profissionais e ao orçamento participativo.

${ }^{10} \mathrm{O}$ survey foi conduzido pelo Centro de Pesquisas Quantitativas em Ciências Sociais (CEPEQS), na Universidade Federal de Minas Gerais (UFMG) (Aguiar, 2005). A amostra foi baseada em três níveis de seleção. Áreas censitárias e domicílios foram selecionados aleatoriamente e o respondente também foi aleatoriamente selecionado entre os membros do domicílio com mais de 18 anos. A amostra inicial foi desenhada para 1.440 casos. A base de dados final incluiu pesos para a correção de viés (Suyama e Fernandes, 2007).

${ }^{11}$ Isso significa que cerca de $10,3 \%$ da amostra foi eliminada (5\% amarelos, 2,5\% indígenas e $2,9 \%$ outros).

12 Todas as análises multivariadas foram computadas com os casos sem a incorporação dos pesos.

${ }^{13}$ As associações comunitárias foram classificadas como políticas pois, em sua maioria, eram associações voltadas para a melhoria do bairro ou de busca de recursos para grupos específicos. Em outras palavras, elas disputavam com outras associações recursos públicos (da prefeitura e de outros órgãos) para sua atuação. 
A variável do chamado ativismo político é composta dos seguintes itens: reunião da comunidade, abaixo-assinado e manifesto, campanhas de arrecadação, boicotes, passeatas, greves e ocupações de prédios.

\section{Variáveis independentes}

Participação não política. As associações classificadas como não políticas são as de caridade, esportivas e recreativas, religiosas, os grupos não religiosos de jovens e de autoajuda e de direitos humanos ${ }^{14}$.

Para essas três variáveis - participação em organizações políticas, ativismo e participação em organizações não políticas - foram criadas variáveis binárias ${ }^{15}$.

Escolaridade $^{16}$. Anos de escolaridade completados com sucesso (ou seja, concluídos e com aprovação) de 0 a 17 anos, incluindo pós-graduação.

Renda. A variável foi construída pela soma da renda men206 sal total do domicílio (não só salários, mas também outros rendimentos advindos de aluguéis, pensão, investimentos etc.) dividida pelo número de habitantes desse domicílio.

\footnotetext{
${ }^{14}$ As associações de direitos humanos foram consideradas como não políticas uma vez que as organizações citadas pelos respondentes, em sua maioria absoluta, são de caridade, sem tomada pública de posição política.

${ }_{15}$ As distribuições das variáveis de participação em organizações políticas e ativistas possuem distribuições bastante distintas das distribuições encontradas por Verba para o caso estadunidense, assim como tampouco são distribuições normais, sendo mais próximas de uma distribuição bimodal (ativismo) e unimodal assimétrica para a direita (para participação em organizações políticas). Dessa maneira, decidiu-se por utilizar uma medida categórica binária para cada uma das variáveis e fazer a análise empírica separadamente para ativismo e participação em organizações políticas. Maneiras alternativas de construção da variável (uso da variável contínua, por exemplo) implicariam uma complexificação (como correções de viés por logaritmo e construção de índices) desnecessária da construção das variáveis e da análise, uma vez que é possível fazer testes homólogos e comparar resultados com os trabalhos de Verba ao se utilizar a formulação mais simples da variável.

${ }^{16}$ Apesar de existirem diferenças entre as ideias de escolaridade e anos de estudo, para os objetivos deste texto, ambas se referem aos recursos adquiridos através da escola. Ao longo do artigo, tais termos são utilizados de forma intercambiável, para evitar repetição.
} 
Raça. Foram utilizadas medidas de autoclassificação racial a partir da categorização oficial do IBGE. Apesar de o questionário permitir o uso de medidas de alter-classificação, escolheu-se trabalhar com autoclassificação, já que é a maneira utilizada na maioria absoluta dos estudos sobre raça e comportamento político no Brasil e ser correntemente utilizada nos estudos sobre desigualdade racial ${ }^{17}$. A partir dessas medidas, foram utilizados dois modos de categorização: "branco, preto e pardo" e "brancos e negros (agregando preto e pardo)". A análise preliminar não mostrou diferenças substantivas nos resultados entre os dois modos de classificação, sendo a principal clivagem revelada pelos dados é entre brancos e não brancos, sem diferenças relevantes entre pardos e pretos em termos de mobilização. Desse modo, para o restante deste artigo, lançou-se mão da categorização binária $^{18}$, que é mais comumente utilizada em análises sobre desigualdades socioeconômicas entre grupos raciais - o que é relevante para a análise ora proposta, cujas medidas de recursos são escolaridade e educação.

\section{Análise dos dados}

$\mathrm{Na}$ amostra de Belo Horizonte, 11,3\% dos respondentes declararam participar de ao menos uma organização política; em termos de ativismo, $69,2 \%$ dos respondentes se declararam como participantes. Dos que declararam participar de alguma atividade política, a maior parte atua em algum sindicato $(4,0 \%)$ ou organização comunitária $(3,8 \%)$, seguidos de associação profissional $(2,8 \%)$, partido político (1,3\%), orçamento participativo $(1,1 \%)$, associações empresariais e

\footnotetext{
17 Ainda que não se rejeite a possibilidade de trabalhar com medidas de alter-classificação (e compará-las com autoclassificação) em trabalhos futuros, para que se possa dialogar com a literatura mais recente sobre formas de classificação e desigualdade social (Bailey, Muniz e Loveman, 2009).

18 Os resultados com a classificação terciária (brancos, pretos e pardos, segundo categorias do IBGE) podem ser encontrados em Bueno (2010).
} 
patronais $(0,9 \%)$, entidade estudantil $(0,6 \%)$ e associação de defesa do consumidor $(0,4 \%)^{19}$. Em relação ao ativismo, os respondentes participam de reunião comunitária $(26,4 \%)$, abaixo-assinados/manifestos $(54,6 \%)$, campanhas de arrecadação $(27,9 \%)$, boicotes $(15,5 \%)$, passeatas $(23,7 \%)$, greves $(14,4 \%)$ e ocupações de edifícios $(1,5 \%)$.

Encontra-se diferença na participação em organizações políticas entre indivíduos de diferentes grupos raciais - sendo brancos $(16,23 \%)$ proporcionalmente mais ativos do que negros $(8,28 \%)$-, ao passo que não se encontra diferença relevante em ativismo político entre brancos $(71,5 \%)$ e negros $(67,8 \%)$.

\section{Tabelas 1:}

\section{Participação política, segundo grupos raciais - Belo Horizonte}

Tabela 1.1.

Participação em organizações políticas

\begin{tabular}{|l|c|c|}
\hline Raça & $\begin{array}{c}\text { Sim } \\
(\%)\end{array}$ & $\begin{array}{c}\text { Não } \\
(\%)\end{array}$ \\
\hline Branco & 16,23 & 83,77 \\
\hline Negro & 8,28 & 91,72 \\
\hline Total & 11,30 & 88,70 \\
\hline
\end{tabular}

Fonte: PRMBH (2005)

Nota: X2 encontrado: 14,99; graus de liberdade: 1
Tabela 1.2.

Ativismo político

\begin{tabular}{|l|c|c|}
\hline Raça & $\begin{array}{l}\text { Sim } \\
(\%)\end{array}$ & $\begin{array}{c}\text { Não } \\
(\%)\end{array}$ \\
\hline Branco & 71,5 & 28,5 \\
\hline Negro & 67,8 & 32,2 \\
\hline Total & 69,2 & 30,8 \\
\hline
\end{tabular}

Fonte: PRMBH (2005)

Nota: X2 encontrado: 1,50;

graus de liberdade: 1

É necessário examinar não só a questão racial, mas verificar se e em que medida os recursos como renda, escolaridade e participação não política, principais formas de

\footnotetext{
${ }^{19}$ Em termos de organizações não políticas, a maioria se declara ativa em associação religiosa $(25,9 \%)$, seguido de associações de caridade $(7,9 \%)$, esportivas ou recreativas $(5,6 \%)$, associações ligadas a temas específicos, como educação e saúde $(4,5 \%)$, associações de direitos de minorias $(3,1 \%)$, grupos de jovens não religiosos $(0,9 \%)$, associações de autoajuda $(0,6 \%)$.
} 
recursos, estão associados à participação política, seja em organizações políticas ou no engajamento em ativismo político. Como se pode ver nas tabelas abaixo, em Belo Horizonte, quanto maior o estrato de renda, em especial os indivíduos com mais do que quatro salários mínimos de renda domiciliar per capita, maior a proporção de indivíduos que são ativos politicamente em organizações políticas. Com relação ao ativismo político, pode-se ver que o aumento na proporção de indivíduos que se mobilizam politicamente aumenta de forma menos intensa. Do mesmo modo, não há uma queda na proporção dos indivíduos atuantes politicamente do estrato de um a dois salários mínimos para indivíduos no grupo de dois a três salários mínimos per capita ${ }^{20}$.

\section{Tabelas 2:}

Participação política, segundo renda familiar per capita - Belo Horizonte

Tabela 2.1.

Participação em organizações políticas

\begin{tabular}{|l|c|c|}
\hline $\begin{array}{l}\text { Renda familiar } \\
\text { per capita }\end{array}$ & $\begin{array}{c}\text { Sim } \\
(\%)\end{array}$ & $\begin{array}{c}\text { Não } \\
(\%)\end{array}$ \\
\hline Até 1 salário mínimo & 6,06 & 93,94 \\
\hline $\begin{array}{l}\text { De 1 a 2 salários } \\
\text { mínimos }\end{array}$ & 5,56 & 94,44 \\
\hline $\begin{array}{l}\text { De 2 a 3 salários } \\
\text { mínimos }\end{array}$ & 18,18 & 81,82 \\
\hline $\begin{array}{l}\text { De 3 a 4 salários } \\
\text { mínimos }\end{array}$ & 11,90 & 8810 \\
\hline $\begin{array}{l}\text { Mais do que 4 salários } \\
\text { mínimos }\end{array}$ & 37,41 & 62,59 \\
\hline Total & 11,3 & 88,7 \\
\hline
\end{tabular}

Fonte: PRMBH (2005)

Nota:X2 encontrado:106,7; graus de liberdade: 4
Tabela 2.2.

Ativismo político

\begin{tabular}{|l|c|c|}
\hline $\begin{array}{l}\text { Renda familiar } \\
\text { per capita }\end{array}$ & $\begin{array}{c}\text { Sim } \\
\text { (\%) }\end{array}$ & $\begin{array}{c}\text { Não } \\
(\%)\end{array}$ \\
\hline Até 1 salário mínimo & 64,2 & 35,8 \\
\hline $\begin{array}{l}\text { De 1 a 2 salários } \\
\text { mínimos }\end{array}$ & 70,6 & 29,4 \\
\hline $\begin{array}{l}\text { De 2 a 3 salários } \\
\text { mínimos }\end{array}$ & 64,6 & 35,4 \\
\hline $\begin{array}{l}\text { De 3 a 4 salários } \\
\text { mínimos }\end{array}$ & 75,6 & 24,4 \\
\hline $\begin{array}{l}\text { Mais do que 4 salários } \\
\text { mínimos }\end{array}$ & 77,2 & 22,8 \\
\hline Total & 69,2 & 30,8 \\
\hline
\end{tabular}

Fonte: PRMBH (2005)

Nota: X2 encontrado: 9,696;

graus de liberdade: 4

${ }^{20} \mathrm{O}$ teste de médias também aponta que indivíduos que participam tem renda média maior do que aqueles que não participam politicamente, tanto em organizações políticas quanto em ativismo político. 
Com relação à escolaridade, encontra-se cenário semelhante: nos estratos de maior escolaridade, há maior a proporção de indivíduos que participam da política. Destaca-se o aumento na proporção politicamente ativa daqueles com ensino superior (completo e incompleto) $)^{21}$.

\section{Tabelas 3:}

Participação política, segundo níveis de escolaridade - Belo Horizonte

Tabela 3.1.

Participação em organizações políticas

\begin{tabular}{|l|c|c|}
\hline Escolaridade & $\begin{array}{c}\text { Sim } \\
(\%)\end{array}$ & $\begin{array}{c}\text { Não } \\
(\%)\end{array}$ \\
\hline 0 a 8 anos & 4,17 & 95,83 \\
\hline 9 a 11 anos & 13,29 & 86,71 \\
\hline Mais de 11 anos & 27,66 & 72,34 \\
\hline Total & 11,30 & 88,70 \\
\hline
\end{tabular}

Fonte: PRMBH (2005)

Nota: X2 encontrado: 90,86; grau de liberdade: 2
Tabela 3.2.

Ativismo político

\begin{tabular}{|l|c|c|}
\hline Escolaridade & $\begin{array}{l}\text { Sim } \\
(\%)\end{array}$ & $\begin{array}{c}\text { Não } \\
(\%)\end{array}$ \\
\hline 0 a 8 anos & 63,9 & 36,1 \\
\hline 9 a 11 anos & 73,4 & 26,6 \\
\hline Mais de 11 anos & 85,0 & 15,0 \\
\hline Total & 69,2 & 30,8 \\
\hline
\end{tabular}

Fonte: PRMBH (2005)

Nota: X2 encontrado: 20,76; graus de liberdade: 2

Com relação à participação em organizações não políticas, encontra-se que há associação entre participação política, nas duas dimensões, e não política. Indivíduos que são ativos em organizações não políticas têm mais chances de também ser ativos politicamente do que indivíduos que não participam de organizações não políticas.

\footnotetext{
${ }^{21}$ Novamente, o teste de médias aponta que indivíduos que participam tem mais anos de escolaridade, em média, do que indivíduos que não participam, tanto para organizações políticas quanto para ativismo.
} 


\section{Tabelas 4:}

Participação política, segundo participação não política - Belo Horizonte

Tabela 4.1.

Participação em organizações políticas

\begin{tabular}{|l|c|c|}
\hline $\begin{array}{l}\text { Participação } \\
\text { não política }\end{array}$ & Sim (\%) & Não (\%) \\
\hline Sim & 19,22 & 80,78 \\
\hline Não & 6,40 & 93,60 \\
\hline Total & 11,30 & 88,70 \\
\hline
\end{tabular}

Fonte: PRMBH (2005)

Nota: X2 encontrado: 39,105, graus de liberdade: 1
Tabela 4.2.

Ativismo político

\begin{tabular}{|l|c|c|}
\hline $\begin{array}{l}\text { Participação } \\
\text { não política }\end{array}$ & Sim (\%) & Não (\%) \\
\hline Sim & 75,74 & 24,26 \\
\hline Não & 65,11 & 34,89 \\
\hline Total & 69,2 & 30,8 \\
\hline
\end{tabular}

Fonte: PRMBH (2005)

Nota: X2 encontrado:12,21;

graus de liberdade: 1

Entretanto, de saída, vários desses atributos estão associados: o pertencimento a certo grupo racial tende a ter padrões fortes de associação com níveis de escolaridade e renda ${ }^{22}$. Portanto, é necessário sofisticar um pouco a análise para se identificar os efeitos e as associações entre as variáveis.

Foram construídos vários modelos de regressão logística para identificar o efeito de cada variável (ver Apêndice). Os modelos foram construídos de maneira a incluir as variáveis relevantes passo a passo e, assim, identificar seus efeitos paulatinamente. Foram construídos quatro modelos para cada variável dependente (ativismo e participação em organizações políticas): 1) raça como única variável independente; 2) renda e escolaridade como variáveis independentes (modelo socioeconômico); 3) raça, renda e escolaridade como variáveis independentes; e 4) modelo completo: raça, renda, escolaridade e participação não política como

\footnotetext{
${ }^{22}$ Em Bueno (2010), estão disponíveis as medidas descritivas básicas sobre raça e recursos, mostrando, de forma singela, que brancos possuem mais renda e escolaridade do que indivíduos negros. Mas, deve-se ressaltar, não se encontra diferença de participação não política entre brancos e negros.
} 
variáveis independentes. Os resultados aqui apresentados se referem ao modelo completo.

Tabela 5:

Participação em organizações políticas e ativismo, por grupo racial Belo Horizonte

\begin{tabular}{|c|c|}
\hline De negro para branco & $\begin{array}{c}\text { Primeira diferença } \\
\text { (com intervalo de 95\% de confiança) }\end{array}$ \\
\hline $\begin{array}{c}\text { Participação em } \\
\text { organizações políticas }\end{array}$ & $-0,005$ \\
$(-0,041,0,032)$
\end{tabular}

Fonte: PRMBH (2005)

Tanto para participação em organizações políticas como em ativismo, pode-se ver que o intervalo da primeira diferença ${ }^{23}$ entre a probabilidade de brancos e negros 212 serem ativos politicamente passa pelo zero. Isso significa que não se encontra diferença substantiva entre brancos e negros na probabilidade de participar de organizações políticas e em ativismo político uma vez que se controla por renda, escolaridade e participação não política ${ }^{24}$. As análises bivariadas não encontraram diferença na participação política entre brancos e negros em termos de ativismo político, mas foram encontradas diferenças relevantes para participação em organizações políticas - o que vai em sentido contrário da tabela acima. No entanto, mais do que saber se raça importa quando renda, escolaridade e participação não política são controladas na média, interessa saber como indivíduos brancos e negros, com diferentes posses de recursos, são propensos a participar politicamente.

\footnotetext{
${ }^{23}$ Ou seja, $\operatorname{Pr}(Y=1 \mid X 1)-\operatorname{Pr}(Y=1 \mid X 0)$.

${ }^{24}$ Mesmo se se considera um intervalo de confiança menos rígido, como $90 \%$.
} 
As tabelas abaixo apresentam as probabilidades esperadas de acordo com os perfis teoricamente relevantes (valores substantivos de interesse). Dessa maneira, pode-se avaliar com um pouco mais de clareza o efeito da raça e sua relação com os recursos como determinantes da participação política. Indivíduos com escolaridade e renda no primeiro quartil são intitulados "baixo"; com escolaridade e renda medianas são denominados "mediano"; e com escolaridade e renda no terceiro quartil são denominados "alto" ${ }^{25}$.

Para a participação em organizações políticas, pode-ser ver pela tabela abaixo que não encontramos diferenças relevantes entre negros e brancos em diversos níveis em termos de posse de recursos ${ }^{26}$, pois há uma sobreposição clara dos intervalos de confiança e valores muito próximos das médias das estimativas de probabilidades. Indivíduos brancos e negros com baixa posse de recursos e que não participam de organizações não políticas têm probabilidade 0,02 de participar; indivíduos brancos e negros com posse média de recursos têm, respectivamente, $0,05 \mathrm{e}$ 0,06 probabilidade de participar (os intervalos de confiança coincidem); e indivíduos brancos e negros com alta posse de recursos (e que não participam de organizações não políticas) têm probabilidade 0,10 de participar. Note-se que, apesar da probabilidade de participar não variar de acordo com o grupo racial, a estimativa média da probabilidade de participar aumenta cinco vezes do grupo com baixos recursos para o grupo com altos recursos. E participar em organização não política aumenta a probabilidade média de participar para todos os níveis de recurso

\footnotetext{
${ }^{25}$ A definição de baixo, mediano e alto, no caso belorizontino, foi aritmética. É baixa aqueles com valor no primeiro quartil (25\%) de renda e escolaridade, mediana aqueles com valores na mediana, ou seja, $50 \%$ dos casos, e alta aqueles com valor no terceiro quartil, $75 \%$.

${ }^{26}$ A primeira diferença, contrastando as probabilidades de um grupo em relação a outro, entre negros e brancos, corrobora esse resultado.
} 
e para brancos e negros. Mas, deve-se destacar, no mesmo nível de recurso, os intervalos de confiança daqueles que participam em organizações não políticas e daqueles que não participam se sobrepõem.

Tabela 6:

Probabilidade de participação em organizações políticas, segundo raça, níveis de recursos e participação não política - Belo Horizonte

\begin{tabular}{|c|c|c|}
\hline & $\begin{array}{c}\text { Não participa em } \\
\text { organização não política } \\
\text { (com intervalo de } 95 \% \text { de } \\
\text { confiança) }\end{array}$ & $\begin{array}{c}\text { Participa em organização } \\
\text { não política } \\
\text { (com intervalo de 95\% de } \\
\text { confiança) }\end{array}$ \\
\hline Branco - baixo & $\begin{array}{c}0,02 \\
(0,01,0,04)\end{array}$ & $\begin{array}{c}0,05 \\
(0,02,0,09)\end{array}$ \\
\hline Branco - mediano & 0,05 & 0,10 \\
\hline Branco - alto & $(0,03,0,08)$ & $(0,05,0,15)$ \\
\hline Negro - baixo & 0,10 & 0,16 \\
$(0,06,0,14)$ & $0,10,0,23)$ \\
\hline Negro - mediano & 0,02 & 0,05 \\
\hline Negro - alto & $(0,017,0,04)$ & $0,02,0,08)$ \\
\hline
\end{tabular}

Fonte: PRMBH (2005)

Com relação a ativismo político, mais uma vez, não há relação nítida entre raça e ativismo político em Belo Horizonte. As probabilidades de participação de brancos e negros são bastante semelhantes para os diversos níveis de recursos, para indivíduos que participam e não participam em organização não política. Por exemplo, indivíduos brancos com valores medianos de recursos e que participam de organizações não políticas tem probabilidade média de participar estimada em 0,63, e indivíduos negros com o mesmo perfil tem probabilidade média estimada em 0,67 (sendo 
que os intervalos se sobrepõem). Quanto maior o nível de recursos, nota-se certo aumento nos valores médios esperados da probabilidade a participar. Apesar desse aumento, ainda há sobreposição entre os intervalos de confiança em diversos níveis, o que indica que o efeito dos recursos é menos intenso para ativismo político do que para participação em organizações políticas.

\section{Tabela 7:}

Probabilidade de engajamento em ativismo, segundo raça, níveis de recursos e participação não política - Belo Horizonte

\begin{tabular}{|c|c|c|}
\hline & $\begin{array}{c}\text { Não participa em } \\
\text { organização não política } \\
\text { (com intervalo de } 95 \% \text { de } \\
\text { confiança) }\end{array}$ & $\begin{array}{c}\text { Participa em organização } \\
\text { não política } \\
\text { (com intervalo de } 95 \% \text { de } \\
\text { confiança) }\end{array}$ \\
\hline Branco - baixo & 0,56 & 0,66 \\
$(0,46,0,65)$ & $(0,57,0,75)$ \\
\hline Branco - mediano & 0,63 & 0,72 \\
$(0,56,0,69)$ & $(0,65,0,79)$ \\
\hline Branco - alto & 0,68 & 0,77 \\
Negro - baixo & $(0,61,0,75)$ & $(0,70,0,82)$ \\
\hline Negro - mediano & 0,61 & 0,70 \\
$(0,55,0,67)$ & $0,77)$ \\
\hline Negro - alto & 0,67 & 0,76 \\
$(0,70,03,0,72)$ & $0,81)$ \\
\hline
\end{tabular}

Fonte: PRMBH (2005)

Os dados ora analisados mostram que, em Belo Horizonte, raça, uma vez controlada por outras variáveis, não mostra efeito relevante na probabilidade de participar. $\mathrm{Ou}$ seja, pertencer a um grupo racial não é suficiente para distinguir aqueles que participam e os que não participam 
politicamente, quando se levam recursos em consideração. Com relação a esses últimos, renda e escolaridade se mostram como os fatores principais para a participação política.

Secundariamente, pode-se concluir que a participação em organizações não políticas se mostra um fator relevante à participação política. Contudo, os problemas de mensuração e potencial endogeneidade fazem com que o achado seja visto com mais cautela. De qualquer maneira, embora esse achado seja significativo, devido à importância do conceito de habilidade cívica na literatura sobre comportamento político e, também, ao fato de a principal participação em organização não política nessa cidade ser em associações religiosas, esse não é o foco deste artigo.

Deve-se notar que também se encontram algumas diferenças entre os resultados para a participação em organizações políticas e o ativismo político. $\mathrm{O}$ modelo baseado em recursos mostrou melhor ajuste ${ }^{27}$ (e estimativas mais preci216 sas) para a participação em organizações políticas do que para o ativismo político, assim como os efeitos das variáveis apresentaram valores mais substantivos nos modelos para organizações políticas do que para ativismo político. Isso pode indicar que o modelo especificado (com raça e recursos) se mostrou mais adequado à participação em organizações políticas. Talvez, o achado seja explicado pelo fato de que participar de organizações seja mais demandante de recursos, como argumentado anteriormente, e o ativismo ter determinantes motivacionais ou contextuais mais relevantes (Norris, 2002).

No entanto, a pergunta substantiva para a literatura sobre raça e comportamento político no Brasil é: Afinal, raça importa? E em que medida raça importa quando controlada pela posição socioeconômica? A resposta a essas perguntas, com base nas evidências analisadas, é: não, o

${ }^{27}$ Para uma discussão mais detalhada sobre ajuste, ver Bueno (2010). 
pertencimento a um grupo racial não afeta de forma substantiva a propensão a atuar politicamente no Brasil, ao passo que fatores socioeconômicos, como renda e escolaridade, são nitidamente mais relevantes. Apesar da importância dessa resposta para aqueles interessados em raça e comportamento político no Brasil, é necessário qualificar seu significado para o modelo baseado em recursos e para a literatura sobre raça e comportamento político.

Ao analisar a relação entre raça e comportamento político, a ênfase explicativa do modelo dos recursos está, como era de se esperar, em apontar os fatores da variação do comportamento político por diferentes grupos raciais. No caso belorizontino, constatou-se que a variação, uma vez controlada por recursos, inexiste. Desse modo, a interpretação do resultado à luz do modelo baseado em recursos tende, de saída, a ser negativa. No caso de Belo Horizonte, não se encontram as condições identificadas no modelo baseado em recursos.

A ausência de fatores como língua, religião e outras habilidades cívicas que levam à variação na participação por diferentes grupos raciais já era documentada na literatura sobre raça e política no Brasil, de modo que a aposta da literatura brasileira está nas experiências de discriminação e preconceito. De acordo com esses autores, essas experiências, mesmo que não se reflitam na formação de consciência de grupo, levariam a um comportamento político diferenciado. Para a literatura baseada em recursos, a aposta é que somente uma experiência de pertencimento a um grupo racial conduz ao compartilhamento de percepções e o desenvolvimento de habilidades que levariam ao comportamento distinto por grupo racial. Se o pressuposto de que a literatura sobre o Brasil está correta - indivíduos que se declaram negros sofrem discriminação e preconceito, e tais situações os levam a um comportamento político diferencial em relação aos que se declaram como brancos -, 
os achados deste artigo não trazem evidências que corroborem de forma significativa a hipótese de que as experiências de discriminação e preconceito levam a um comportamento político diferenciado agregado.

Mas, pode-se argumentar, os trabalhos de Verba e seus colaboradores não parece fornecer pistas satisfatórias para a explicação dos resultados de Belo Horizonte a não ser por uma interpretação negativa, que acusa a ausência das condições estabelecidas pelos modelos produzidos por tais autores. Seria, então, Belo Horizonte (e, em certo sentido, o Brasil) o "não caso" ou, na melhor das alternativas, um caso-controle no qual raça não se expressa politicamente de forma relevante? Ou é possível apresentar alternativas para a interpretação dos resultados encontrados em Belo Horizonte segundo a perspectiva adotada?

Uma saída para a defesa da análise centrada em recursos é notar que, para que essas hipóteses sejam efetivamente 218 testadas, seria necessário investir na identificação das medidas concernentes aos mecanismos psicológicos que afetam o comportamento político. Esse exercício poderia trazer um refinamento dos achados de Belo Horizonte e, possivelmente, um melhor entendimento dos mecanismos pelos quais raça opera no Brasil.

Tendo em vista os resultados encontrados, é possível indicar ao menos uma orientação para proposições sobre raça e comportamento político: os modelos e hipóteses sobre a relação entre raça e comportamento político devem ser contingentes aos significados das categorias raciais na polity sob análise. Esse tipo de consideração impede que uma teorização, a princípio geral, sobre a relação entre raça e comportamento político, tenha pressupostos que impeçam sua operação em diversos objetos (polities) sob análise. Dado que diversos países podem ser classificados de acordo com seus padrões de categorização racial a partir de algum critério (por exemplo, países mais ou menos per- 
missivos em termos de miscigenação, com classificações baseadas em ascendência versus fenótipo ou ainda por tipos de sistemas classificatórios, binários versus de múltiplas categorias), seria possível criar uma tipologia acerca dos sistemas de categorias raciais e seus efeitos na mobilização política. Desse modo, a partir dos padrões de categorização racial de cada polity, seria possível encontrar, dentro das diversas vertentes de estudo sobre comportamento político e raça, quais mecanismos são mais ou menos plausíveis. Assim, a relação entre raça e recursos socioeconômicos, por exemplo, seria definida a partir do desenvolvimento de uma tipologia da relação entre essas clivagens; afinal, diferentes combinações de clivagens podem gerar resultados distintos e, assim, tornar mecanismos (institucionais, políticos, contextuais e psicológicos) mais ou menos plausíveis.

Deve-se notar que está além dos objetivos deste texto esboçar proposições dessa natureza, mas dada a relevância das relações raciais para a mobilização política em diversas partes do mundo e considerando-se que a abordagem baseada em recursos é extremamente bem-sucedida em descrever a configuração da participação política em diversos países, nada mais natural do que apontar para caminhos que elevem a teorização sobre o papel da raça na atuação política para o mesmo nível de generalização do que a abordagem pautada em recursos fez para recursos políticos.

\section{Natália S. Bueno}

é doutoranda em Ciência Política pela Universidade de Yale.

\section{Referências bibliográficas}

ACHEN, C. 1992. "Breaking the iron triangle: social psychology, demographic variables and linear regression in voting research". Political Behavior, vol. 14, no 3, pp. 195-211.

ANDREWS, G. R. 1991. "O protesto político negro em São Paulo: 18881988”. Estudos Afro-Asiáticos, no 21, pp. 27-48. 
1996. "Brazilian racial democracy, 1900-90: an American counterpoint”. Journal of Contemporary History, vol. 31, no 3, pp. 483-507.

BAILEY, S. R. 2008. "Unmixing of race making in Brazil". American Journal of Sociology, vol. 114, no 3, pp. 577-614.

2009. "Public opinion on nonwhite underrepresentation and racial identity politics in Brazil”. Latin American Politics and Society, vol. 51, no 4, pp. 69-99.

; MUNIZ, J. O.; LOVEMAN, M. 2009. "The measure of 'race' and the estimation of racial inequality". Texto apresentado no XXXIII Encontro da Anpocs. Caxambu (mimeo).

BERQUÓ, E.; ALENCASTRO, L. F. 1992. “A emergência do voto negro”. Novos Estudos Cebrap, no 33, pp. 77-88.

BOBO, L.; GILLIAM, F. 1990. "Race, sociopolitical participation, and black empowerment”. The American Political Science Review, vol. 84, no 2, pp. 377-393.

BOWERS, J. 2008. "Events into action: a framework for studying political participation as a dynamic process". Disponível em $<$ http:/ / www.jakebowers.org> Acesso em 08/2009.

BUENO, N. S. 2010. Raça e comportamento político em perspectiva comparada: evidências de Belo Horizonte e da Cidade do Cabo. Dissertação de Mestrado em Ciência Política. São Paulo: FFLCH-USP.

; FIALHO, F. M. 2009. "Race, resources, and political participation in a Brazilian city”. Latin American Research Review, vol. 44, no 2, pp. 59-83.

CARDOSO, M. A. 2001. O movimento negro em Belo Horizonte: 1978-1998. Belo Horizonte: Maza Edições.

CASTRO, M. M. M. 1993. "Raça e comportamento político". Dados, vol. 36, no 3, pp. 469-491.

CHANDRA, K. 2006. "What is ethnic identity and does it matter?". Annual Review of Political Science, vol. 9, pp. 397-424.

CHO, W. K.; GIMPEL, J. G.; WU, T. 2006. "Clarifying the role of SES in political participation: policy threat and Arab American mobilization". The Journal of Politics, vol. 68, n 4, pp. 977-991.

CHONG, D.; ROGERS, R. 2003. "Reviving group consciousness" (mimeo.). 2005. "Racial solidarity and political participation". Political Behavior, vol. 27, no 4, pp. 347-373.

CHONG, D.; KIM, D. 2006. "The experiences and effects of economic status among racial and ethnic minorities”. American Political Science Review, vol. 100, no 3, pp. 335-351.

DALTON, R. J.; KLINGEMANN, H. 2007. Oxford handbook of political behavior. Nova York: Oxford University Press. 
FUKS, M.; PERISSINOTTO, R. 2006. "Recursos, decisão e poder: conselhos gestores de políticas públicas de Curitiba”. Revista Brasileira de Ciências Sociais, vol. 21, pp. 67-81.

GOODIN, R. E.; KLINGEMANN, H. 1996. A new handbook of political science. Nova York: Oxford University Press.

GUIMARÃES, A. S. A. 2002. Classes, raças e democracia. São Paulo: Ed. 34. 2003. "The race issue in Brazilian politics (the last fifteen years)". In: KINZO, M. D.; DUNKERLEY, J. (orgs.). Brazil since 1985: economy, polity and society. London: Institute of Latin American Studies. 2008. Preconceito racial: modos, temas e tempos. São Paulo: Cortez.

HANCHARD, M. G. 1993. "Culturalism versus cultural politics: movimento negro in Rio de Janeiro and São Paulo, Brazil”. In: WARREN, K. B. (org.). The violence within: cultural and politics opposition in divided nations. Boulder: Westview Press.

2001. Orfeu e o poder: movimento negro no Rio de Janeiro e São Paulo. Rio de Janeiro: Ed. Uerj.

HASENBALG, C. 2005. Discriminação e desigualdades raciais no Brasil. Belo Horizonte: Ed. UFMG; Rio de Janeiro: Iuperj.

; VALLE SILVA, N.; LIMA, M. 1999. Cor e estratificação social. Rio de Janeiro: Contra Capa.

HTUN, M. 2004. "From racial democracy to affirmative action: changing State policy on race in Brazil”. Latin American Research Review, vol. 39, no 1, pp. 60-98.

HUTCHINGS, V. L.; VALENTINO, N. A. 2004. "The centrality of race in American politics”. Annual Review of Political Science, vol. 7, pp. 383-408.

IBGE. s.d. "Censo Demográfico 2000: características da população e dos domicílios: resultados do universe". Disponível em <http://www.ibge.gov. $\mathrm{br} /$ home/estatistica/populacao/censo2000>. Acesso em 01/08/2010.

INGLEHART, R.; NORRIS, P. 2003. Rising tide: gender equality and cultural change around the world. Cambridge: Cambridge University Press.

JOHNSON, O. A. 1998. "Racial representation and Brazilian politics: black members of the National Congress, 1983-1999". Journal of Interamercan Studies and World Affairs, vol. 40, no 4, pp. 97-118.

2006. "Locating blacks in Brazilian politics: Afro-Brazilian activism, new political parties, and pro-black public policies”. International Journal of Africana Studies, vol. 12, no 2, pp. 170-193.

LAMOUNIER, B. 1968. "Raça e classe na política brasileira". Cadernos Brasileiros, vol. 47, pp. 39-50.

LEIGHLEY, J. E. 1995. "Attitudes, opportunities and incentives: a field essay on political participation”. Political Research Quarterly, vol. 48, pp. 181-209. 
2008. "Commentary on attitudes, opportunities and incentives: a field essay on political participation”. Political Research Quarterly, vol. 61, pp. 46-49.

LEIGHLEY, J. E.; VEDLITZ, A. 1999. "Race, ethnicity, and political participation: competing models and contrasting explanations". Journal of Politics, vol. 61, no 4, pp. 1092-1114.

; MATSUBAYASHI, T. 2009 "The implications of class, race, and ethnicity for political networks”. American Politics Research, vol. 37, nº 5, pp. 824-855.

McADAM, D. 1982. Political process and the development of black insurgency, 1930- 1970. Chicago: The University of Chicago Press.

McClain, P.; CAREW, J.; WALTON, E.; WATTS, C. 2009. "Group membership, group identity, and group consciousness: measures of racial identity in American politics". Annual Review of Political Science, vol. 12, pp. 471-485.

MILLER, A. H.; GURIN, P.; GURIN, G.; MALANCHUK, O. 1981. "Group consciousness and political participation”. American Journal of Political Science, vol. 25, pp. 494-511.

MITCHELL, G. 2009. "Afro-Brazilian politicians and campaign strategies: a preliminary analysis”. Latin American Politics and Society, vol. 51, nº 3, pp. 111-142.

MUNIZ, J. O. 2010. "Sobre o uso da variável raça-cor em estudos quantitativos”. Revista de Sociologia e Política, vol. 18, no 36, pp. 277-291.

NORRIS, P. 2002. Democratic phoenix: reinventing political activism. Cambridge: Cambridge University Press.

OLIVEIRA, C. 1997. A luta por um lugar: gênero, raça, e classe, eleições municipais de Salvador, Bahia, 1992. Salvador: Programa a Cor da Bahia/UFBA.

2007. A inevitável visibilidade de cor: estudo comparativo das campanhas de Benedita da Silva e Celso Pitta às prefeituras do Rio de Janeiro e São Paulo, nas eleições de 1992 e 1996. Tese de Doutorado em Ciência Política. Rio de Janeiro: Iuperj.

PASCHEL, T.; SAWYER, M. Q. 2008. "Contesting politics as usual: black social movements, globalization, and race policy in Latin America”. Souls, vol. 10, nº 3, pp. 197-214.

PRANDI, R. 1996. "Voto e raça na eleição presidencial de 1994". Estudos Afro-Asiáticos, vol. 30, pp. 61-78.

REIS, F. W. 2000. Mercado e utopia: teoria política e sociedade brasileira. São Paulo: Edusp. 2001. "Política e participação: notas sobre aspectos doutrinários e 
empíricos”. Revista USP, vol. 49, pp. 6-23.

RIBEIRO, E. A.; BORBA, J. 2011. "Protesto político na América Latina: bases individuais e estruturais". Texto apresentado no XXVIII Congresso da Alas. Recife (mimeo.).

RIOS, F. M. 2008. A institucionalização do movimento negro no Brasil contemporâneo. Dissertação de Mestrado em Sociologia. São Paulo: FFLCH-USP.

SANSONE, L. 2003. Blackness without ethnicity: constructing race in Brazil. Nova York: Palgrave/St. Martin's Press.

SANTOS, J. A. F. 2005. "Efeitos de classe na desigualdade racial no Brasil". Dados, vol. 48, no 1, pp. 21-63.

SANTOS, S. A. 2000. A ausência de uma bancada suprapartidária afro-brasileira no congreso nacional (legislatura 1995-1998). Brasília: Centro de Estudos Afro-Asiáticos (2 vols.).

SAWYER, M. 2005. “'Race' to the future: racial politics in Latin America 2015”. Perspectives on Politics, vol. 3, no 3, pp. 561-564.

SCHLOZMAN, K. L. 2002. "Citizen participation in America: what do we know? Why do we care?”. In: KATZELSON, I.; MILNER, H. V. (orgs.). Political science: state of the discipline. Nova York: Norton and Company/ American Political Science Association.

SEGURA, G. M.; RODRIGUES, H. A. 2006. "Comparative ethnic politics in the United States: beyond black and white". Annual Review of Political Science, vol. 9, pp. 375-395.

SHINGLES, R. D. 1981. "Black consciousness and political participation: the missing link". The American Political Science Review, vol. 75, nำ 1 , pp. 76-91.

SOARES, G.; VALLE SILVA, N. 1987. "Urbanization, race, and class in Brazilian politics”. Latin American Research Review, vol. 22, no 2, pp. 155-176.

SOARES, G.; VALLE SILVA, N. 1985. "O charme discreto do socialismo moreno”. Dados, v. 28, no 2, pp. 253-273.

SOUZA, A. 1971. "Raça e política no Brasil urbano". Revista de Administração de Empresas, vol. 11, no 4, pp. 61-70.

SOUZA, J. 2006. "Raça ou classe? Sobre a desigualdade brasileira". Lua Nova, no ${ }^{\circ}$, pp. 43-70.

SUYAMA, E.; FERNANDES, R. A. 2007. "Planejamento da amostra, seleção de unidades amostrais, e sistema de ponderação da pesquisa da região metropolitana de Belo Horizonte”. In: AGUIAR, N. (org.). Desigualdades sociais, redes de sociabilidade e participação política. Belo Horizonte: Ed. UFMG.

TIMPONE, R. J. 1998. "Ties that bind: measurement, demographics, and social connectedness". Political Behavior, vol. 20, nº 1, pp. 53-77. 
TELLES, E. E. 1996. "Identidade racial, contexto urbano e mobilização política”. Afro-Ásia, vol.17, pp. 121-138.

2003. Racismo à brasileira: uma nova perspectiva sociológica. Rio de Janeiro: Fundação Ford/Relume Dumará.

VERBA, S.; NIE, N. H. 1972. Participation in America: political democracy and social inequality. Chicago: University of Chicago Press. ; __ KIM, J. 1979. Participation and political equality: a seven-nation comparison. Chicago: University of Chicago Press. ; SCHLOZMAN, K. L.; BRADY, H. E. 1995. Voice and equality: civic voluntarism in American politics. Cambridge: Harvard University Press. ; __ ; _ NIE, N. H. 1993. "Race, ethnicity and political resources: participation in the United States". British Journal of Political Science, vol. 23, no 4, pp. 453-497.

WRINKLE, R. D.; STEWART JR., J.; POLINARD, J. L.; MEIER, K. J.; ARVIZU, J. R. 1996. "Ethnicity and nonelectoral political participation”. Hispanic Journal of Behavioral Sciences, vol.18, no 2, pp. 142-153.

\section{Outros materiais}

AGUIAR, N. 2005. Pesquisa da Região Metropolitana de Belo Horizonte 2005. Base de dados. Centro para Pesquisa Quantitativa em Ciências Sociais-UFMG. 


\section{Apêndice: Modelos de regressão}

Tabela A.1:

Modelos de regressão logística -

Participação em organizações políticas

\begin{tabular}{|c|c|c|c|c|}
\hline & $\begin{array}{l}\text { Modelo 1: } \\
\text { raça }\end{array}$ & $\begin{array}{c}\text { Modelo 2: } \\
\text { socioeconômico }\end{array}$ & $\begin{array}{c}\text { Modelo 3: } \\
\text { raça + } \\
\text { socioeconômico }\end{array}$ & $\begin{array}{c}\text { Modelo 4: } \\
\text { raça + } \\
\text { socioeconômico } \\
\text { + participação } \\
\text { não política }\end{array}$ \\
\hline $\begin{array}{c}\text { Raça } \\
\text { (branco) }\end{array}$ & $\begin{array}{l}0,443^{* *} \\
(-0,217)\end{array}$ & & $\begin{array}{l}-0,107 \\
(-0,266)\end{array}$ & $\begin{array}{c}-0,09 \\
(-0,266)\end{array}$ \\
\hline $\begin{array}{c}\text { Logaritmo } \\
\text { da renda per } \\
\text { capita }\end{array}$ & & $\begin{array}{c}0,406 * * * \\
(-0,143)\end{array}$ & $\begin{array}{c}0,421 * * * \\
(-0,148)\end{array}$ & $\begin{array}{c}0,393 * * * \\
(-0,147)\end{array}$ \\
\hline $\begin{array}{c}\text { Anos de } \\
\text { escolaridade }\end{array}$ & & $\begin{array}{c}0,13555 * * * \\
(-0,04)\end{array}$ & $\begin{array}{c}0,136^{* * *} \\
(-0,04)\end{array}$ & $\begin{array}{c}0,130 * * * \\
(-0,04)\end{array}$ \\
\hline $\begin{array}{c}\text { Participação } \\
\text { não política }\end{array}$ & & & & $\begin{array}{c}0,615 * * \\
(-0,247)\end{array}$ \\
\hline Intercepto & $\begin{array}{c}-2,409 * * * \\
(-0,142)\end{array}$ & $\begin{array}{c}-5,901^{* * *} \\
(-0,739)\end{array}$ & $\begin{array}{c}-5,963 * * * \\
(0,756)\end{array}$ & $\begin{array}{c}-6,018^{* * *} \\
(-0,756)\end{array}$ \\
\hline $\mathrm{N}$ & 997 & 781 & 781 & 781 \\
\hline AIC & 631,73 & 477,65 & 479,48 & 475,31 \\
\hline
\end{tabular}

Fonte: PRMBH (2005)

p-valor: $0,001 * * * 0,01 * * 0,05 * 0,1$. 
Tabela A.2:

Modelos de regressão logística - Ativismo político

\begin{tabular}{|c|c|c|c|c|}
\hline & $\begin{array}{c}\text { Modelo 1: } \\
\text { raça }\end{array}$ & $\begin{array}{c}\text { Modelo 2: } \\
\text { socioeconô- } \\
\text { mico }\end{array}$ & $\begin{array}{l}\text { Modelo 3: } \\
\text { raça + socioe- } \\
\text { conômico }\end{array}$ & $\begin{array}{c}\text { Modelo 4: } \\
\text { raça + } \\
\text { socioeconô- } \\
\text { mico + parti- } \\
\text { cipação não } \\
\text { política }\end{array}$ \\
\hline $\begin{array}{c}\text { Raça } \\
\text { (Branco) }\end{array}$ & $\begin{array}{c}0,072 \\
(0,147)\end{array}$ & & $\begin{array}{l}-0,194 \\
(0,174)\end{array}$ & $\begin{array}{l}-0,203 \\
(0,175)\end{array}$ \\
\hline $\begin{array}{c}\text { Logartimo } \\
\text { da renda per } \\
\text { capita }\end{array}$ & & $\begin{array}{l}0,152^{*} \\
(0,092)\end{array}$ & $\begin{array}{l}0,177^{*} \\
(0,095)\end{array}$ & $\begin{array}{l}0,164^{*} \\
(0,095)\end{array}$ \\
\hline $\begin{array}{c}\text { Anos de } \\
\text { escolaridade }\end{array}$ & & $\begin{array}{c}0,052^{* *} \\
(0,023)\end{array}$ & $\begin{array}{c}0,052^{* *} \\
(0,023)\end{array}$ & $\begin{array}{c}0,048^{* *} \\
(0,023)\end{array}$ \\
\hline $\begin{array}{l}\text { Participação } \\
\text { Não política }\end{array}$ & & & & $\begin{array}{c}0,434^{* *} \\
(0,171)\end{array}$ \\
\hline Intercepto & $\begin{array}{c}0,792^{* * *} \\
(0,085)\end{array}$ & $\begin{array}{l}-0,437 \\
(0,462)\end{array}$ & $\begin{array}{l}-0,513 \\
(0,468)\end{array}$ & $\begin{array}{l}-0,560 \\
(0,472)\end{array}$ \\
\hline $\mathrm{N}$ & 966 & 778 & 778 & 778 \\
\hline AIC & 1194,3 & 935,35 & 936,1 & 931,5 \\
\hline
\end{tabular}

Fonte: PRMBH (2005)

p-valor: $0,001 * * * 0,01 * * 0,05 * 0,1$. 


\title{
RAÇA E COMPORTAMENTO POLÍTICO: PARTICIPAÇÃO,
} ATIVISMO E RECURSOS EM BELO HORIZONTE

\author{
NATÁLIA S. BUENO
}

Resumo: A discussão sobre raça na política brasileira é mote entre cientistas sociais de diversas perspectivas: seja pelo seu papel na formação do Estado nacional, nos movimentos sociais ou ainda nas políticas públicas voltadas a grupos 
raciais. Utilizando a abordagem centrada em recursos, argumenta-se que o pertencimento a um grupo racial não afeta de forma substantiva a propensão a atuar politicamente em Belo Horizonte, ao passo que fatores socioeconômicos, como renda e escolaridade, são nitidamente mais relevantes. Esses resultados empíricos, por sua vez, não eliminam o fato de que a abordagem dos recursos apresenta limitações para testar os fatores que levariam à mobilização racialmente orientada no Brasil.

Palavras-chave: Raça; Belo Horizonte; Recursos; Participação política; Ativismo.

\section{RACE AND POLITICAL BEHAVIOR: PARTICIPATION, ACTIVISI, AND RESOURCES IN BELO HORIZONTE}

Abstract: Social scientists approach the role of race in Brazilian politics from diverse perspectives: its role in the making of the nation-state, social movements, or race-targeted public policies. This paper takes on race as a central issue and looks into race's effect on individual political behavior. Using the resource-based approach as a framework, races does not seem to affect an individual's chance of participating politically in Belo Horizonte, whereas the possession of resources such as income and education substantially increases an individual's likelihood of participation. Despite these findings, it is argued that the resource-based approach has a limited capacity to test all factors that lead to political behavior influenced by racial identity.

Keywords: Race; Belo Horizonte; Resources; Political behavior; Activism.

Recebido: 02/08/2011 Aprovado: 03/10/2011 